\title{
Deaf people: what every clinician needs to know
}

\section{Margaret du Feu}

\begin{abstract}
SUMMARY
Deafness is a common and varied medical, social and psychological construct that affects a significant proportion of the population. Restricted communication and uninformed attitudes have adverse effects on the physical and mental health of deaf people. Clinicians need to know how to recognise and resolve these difficulties.
\end{abstract}

\section{LEARNING OBJECTIVES}

- Be aware of the high prevalence and diverse nature of deafness

- Recognise the importance of effective communication and how to achieve this with deaf people

- Understand the potential impact of deafness on mental and physical health

\section{DECLARATION OF INTEREST}

None

The facts about deafness described in purely audiological terms are easily stated. The World Health Organization (2015) identifies 360 million people worldwide with disabling hearing loss. In high-income countries such as the UK, one in six people are affected by deafness (Action on Hearing Loss 2015), including up to one in three older people. Common causes of deafness are shown in Box 1. Degrees of deafness are shown in Box 2.

\section{BOX 1 Common causes of deafness}

\section{Early profound Deafness}

- 50\% genetic: mainly recessive, about 100 genes identified; some genes have one or more additional effects, including neurological, physical or sight problems and intellectual disability

- 50\% non-genetic: birth anoxia, cytomegalovirus, meningitis, neonatal jaundice, ototoxic drugs, prematurity, prenatal rubella

\section{Acquired deafness}

Causes include: age-related changes in the cochlea, head injury, infectious diseases, Ménière's disease, middle-ear infections, noise exposure

\section{Terminology}

It is important to use the correct terminology about people who are deaf. Terms used in the past to refer to some ethnic or disabled groups are now acknowledged as totally inappropriate, if not actually offensive, and the same applies to deaf people. Terms such as 'deaf and dumb' and 'deaf mute', which imply that deaf people are stupid or inarticulate, must be completely discarded. The term 'hearing impaired' is still widely used, but deaf people themselves prefer deaf, deafened or hard of hearing.

People who have been profoundly deaf from early life (one in a thousand of the general population) and use their national sign language identify themselves as a cultural/linguistic community and describe themselves as Deaf, with a capital D.

\section{BOX 2 Degrees of deafness}

Four levels of hearing loss are defined by the quietest sound that can be heard, measured in decibels (dB).

\section{Mild hearing loss}

- Quietest sound: 25-39dB

- This can make following speech difficult, particularly in noisy situations or for long periods of time. People start avoiding social situations.

Moderate hearing loss

- Quietest sound: 40-69dB

- People often have difficulty following speech without hearing aids. They are likely to avoid most or all social situations.

\section{Severe hearing loss}

- Quietest sound: 70-94 dB

- People usually need to lipread or use sign language, even with hearing aids. They may be eligible for cochlear implants.

\section{Profound deafness}

- Quietest sound: $95 \mathrm{~dB}$

- People usually need to lipread or use sign language. Hearing aids are often not helpful, but the person may benefit from cochlear implants.

(Based on Action on Hearing Loss 2015: p. 23)

\section{ARTICLE}

Margaret du Feu qualified in 1978 from Cambridge University and the Royal London Hospital. She has worked as consultant psychiatrist in mental health and deafness services in Birmingham (1991-2005) and Northern Ireland (2003-2010) and, since 2005, in the Republic of Ireland. She has been progressively deafened by cochlear otosclerosis and received a cochlear implant in 1999. She uses British and Irish Sign Languages.

Correspondence Dr Margaret du Feu, c/o BJPsych Advances, The Royal College of Psychiatrists, 21 Prescot Street, London E1 8BB, UK. Email: margaret.dufeu@gmail.com

\section{Copyright and usage}

(c) The Royal College of Psychiatrists 2017. 


\title{
Communication
}

Every clinical interaction depends on communication. This can be seriously limited or distorted when the patient is deaf. It is vital to keep an open mind, to ask what patients want or need for full two-way communication, and to provide it.

When meeting a Deaf, deafened or hard of hearing person, a hearing clinician encounters the interface between them. Deaf people experience this interface all the time, even within their own families:

\begin{abstract}
A young Deaf mother always asked her hearing sister to come with her when she took her baby out in his stroller. When her sister moved away, the mother would not go out with him. She explained that people would look at the baby and smile and say something, and she never knew what they were saying, or even if they were talking to her or to someone else. She did not want to be rude, but did not know how to respond, so she avoided going out.
\end{abstract}

All too often, hearing clinicians feel deskilled and struggle to avoid frustration and impatience. For the deaf person, the situation is familiar, but there is also frustration, as well as emotions such as anger, avoidance or resignation. Recognition and acknowledgement of the communication

BOX 3 Tips for communicating with hard of hearing people

- The speaker's mouth should be visible without barriers such as a surgical mask or distractions such as frequent movements. During a medical consultation, the patient will not be able to follow the clinician when the eyes, ears or back are being examined.

- The speaker should be at a comfortable distance, not too far away for speech reception and not too close for lipreading. About 4-5 feet (1.2-1.5 m) is usually best.

- The deaf person needs to look at the speaker. Make sure that there is eye contact before starting to speak, and pause if the person looks away, for example to look at written material.

- There should be no background noise or visual distractions. Avoid settings that have poor acoustics, such as large areas with hard surfaces.

- The deaf person should not have to look into the light, as this puts the speaker's face in shadow.

- The speaker should speak at a normal pace (not too quickly, but not artificially slowly) and at normal volume. Shouting can be painful, and distorts lip patterns. bottleneck or barrier is the first step to overcoming it (Middleton 2009). Deaf awareness training is provided by many Deaf organisations (e.g. www.actiononhearingloss.org.uk; www. deafhear.ie). This gives information about positive attitudes, communication strategies, sign language interpreters, and assistive technology such as 'speech to text' and visual or vibrating alarm systems.

It is often thought that the key problem for people with acquired deafness is the literal reduction in auditory perception, like listening to the radio with the sound turned down. However, a more apt analogy would be watching television with loud background music, poor reception and no subtitles. Deaf people have difficulty screening out background noise, and may have troublesome hyperacusis, either from the cause of the deafness or from their hearing aids. They need to 'hear with their eyes', using lipreading and visual cues (Box 3).

Clinicians who do not sign need an interpreter with Deaf patients. It cannot be assumed that a Deaf signer can lipread or is literate in English, which is not their first language. Clinicians are often more familiar with working with spoken language interpreters, and need to understand how to use sign interpretation (Box 4). It is well recognised that even bilingual people give a fuller history in their first language (Farooq 2003). Nelson Mandela wrote: 'If you talk to a man in the language he knows, that goes to his head, if you talk to him in his own language, that goes to his heart' (Mandela 2011: p. 144).

\section{BOX 4 Communication tips - Deaf signers}

- The tips for communicating with hard of hearing people (Box 3) all apply. In addition, the clinician needs to know how to work with a sign language interpreter.

- For professional and medical appointments a qualified registered sign language interpreter must be used.

- Relatives should not be used as interpreters.

- The interpreter should sit next to the hearing person and opposite the Deaf person. This means the Deaf person can face the speaker while watching the interpreter, and the speaker looks at and addresses the Deaf person.

- The interpreter will interpret everything that is said or signed, so no side conversations can take place.

- Speech should be at a normal pace and volume. The interpreter will indicate if they cannot hear or keep up.

- Be unhurried, positive and friendly. Deaf people are sensitive to when people become impatient with them and they can pretend to understand, to placate the interviewer and/or to end the consultation.
- Speech should not include long complicated sentences, double negatives, compound questions or idioms. Topic changes should be well indicated. 


\section{Deaf people in society}

It is well documented that Deaf, deafened and hard of hearing people can experience social exclusion, with reduced opportunities in education and employment. They encounter many barriers to equality of access to public services, including health services (Action on Hearing Loss 2015):

A hard of hearing mother telephoned her doctor to ask for an urgent visit for her young son with abdominal pain. She heard the phone being answered and gave the details clearly. The doctor did not arrive and when her son's condition worsened she took him to hospital. She was asked why she had not contacted her GP. It transpired that she had not been talking to the receptionist but to a recorded message.

Deaf people have been shown to be at increased risk of physical illnesses, such as epilepsy and heart disease, associated with some causes of deafness. They are also at increased risk of undetected or poorly managed common conditions such as hypertension and diabetes because of poor access to health information and reduced access to and effective communication with medical services (Sign Health 2014).

People who are Deaf signers, and those who use hearing aids and lipreading, are at increased risk of mental health problems, including depression and adjustment disorders (du Feu 2003; Kvam 2006; Fellinger 2012). To put this into context, it is vital to understand the individual deaf person's path through life. Deaf people can have increased neurological risk associated with the cause of the deafness. They may have been at higher risk in childhood and adult life from social isolation, negative attitudes and poor communication. Deaf signers, in particular, are likely to experience prolonged delays before reaching appropriate services for accurate diagnosis and treatment of mental health problems. Even then, communication problems can compromise treatment:

A Deaf man with depressive illness was slowly improving on medication. He went to pick up a month's repeat prescription. The pharmacist handed him a paper bag containing a small packet of only five tablets. On the bag a printed message stated that 'There is insufficient medication in stock. Please collect the remainder of your prescription when convenient'. The man, whose first language was British Sign Language, did not understand what the pharmacist said, and could only read simple English. He therefore assumed that his medication had been stopped and his illness relapsed.

\section{Acquired deafness}

People with deafness acquired in adult life, especially if it is severe or sudden, can have a bereavement reaction of denial, anger and depression. Beethoven (1802) famously wrote: 'I must live quite alone [...]. I must live like an outcast'. Modern hearing aids and implants can alleviate this isolation to a variable extent, but barriers remain. There is a stigma attached to deafness, which means that people may wait up to 10 years before seeking help (Action on Hearing Loss 2015). Hearing aids are not like glasses, which can be fashionable, work instantly and have no unwanted effects. Hearing aids can be painful to wear, are thought of negatively as a mark of old age, and amplify unwanted background noise. Group situations and public areas such as shops and restaurants are difficult and exhausting:

A man with acquired partial hearing loss found his hearing aids painful to wear owing to the excess background noise they picked up. He said 'It is like a thousand sheep grazing in my ears'.

A deafened woman with powerful hearing aids described going into a busy restaurant as 'being dropped into the middle of a brass band playing in an echo chamber'.

A deaf man with new hearing aids said that the first time he ate celery while wearing them was 'like hearing a herd of elephants gallop down a glacier'.

People usually respond helpfully to someone with sight problems, but can be patronising, impatient and dismissive towards a person with hearing loss. Being deaf needs confidence and concentration, and the ability to deal with the uncertainty of never knowing what has been missed. It is not surprising that many people find that their resilience is eroded. Some people retreat into a small social or family setting, and may become dependent on a few people that they can communicate effectively with. This also affects close family members, who may feel that they have lost their own voice (LINK 2005).

\section{Early profound deafness}

More than $90 \%$ of Deaf signers, who have been profoundly deaf from birth or early life, are from hearing families. They may have had access to sign language only after reaching adult life, as until the recent past, many educational policies for the education of deaf children have forbidden sign and concentrated, often unsuccessfully, on oral teaching (speech and lipreading). Language delays and difficulties have had adverse consequences for the education, literacy, and emotional and psychological health of many Deaf people (Sacks 1991; Denmark 1994; du Feu 2014). However, the resilience of the Deaf community, equality legislation (such as the United Nations Convention on the Rights of Persons with Disabilities in 2006 and the UK's Equality Act 2010), the development of bilingual education and the recognition of 
BOX 5 Living with the legacy of the past

Patrick Griffin, whose painting is on the cover of this issue of BJPsych Advances, was born profoundly Deaf in 1943 in a psychiatric hospital in rural Ireland to a mother with schizophrenia. He was removed at birth and remained in institutional care all his life. He was given no access to either speech or Irish Sign Language. He was found in long-stay psychiatric care in his 30 s by nuns from a Deaf residence in Dublin. Patrick has a normal 10 and no mental illness , but his transfer to a signing environment was refused by his psychiatrist. He was found again by social workers with Deaf people in his 60s, and attempts were made to teach him some signs, but it was too late for him to develop a first language. He was eventually moved to the Dublin Deaf Residence in 2015 , where he is very happy. He has always expressed himself through painting.

national sign languages as full languages (Stokoe 1976) all mean that Deaf people are taking their rightful place in society. There is still a long way to go (for example, although Irish Sign Language is recognised by the European Union and in Northern Ireland, it is not yet recognised as a national language in the Republic of Ireland) and Deaf people are still living with the legacy of past policies and attitudes (Box 5). This means that an individual Deaf person may not be fluent in sign, and even the sign they know may have fallen into disuse if they have become socially isolated.

\section{Deaf children and adolescents}

Children can have profound, partial or intermittent hearing loss. Each of these can have a negative effect on language acquisition and on age-appropriate social, emotional, psychological and academic development. Early recognition of deafness through neonatal and regular screening is vital. The World Health Organization (2016) recommends hearing technology, including hearing aids and cochlear implants, access to sign language, and parent and family support groups to facilitate social inclusion.

Deaf children have an increased risk of mental health problems (Gentili 2011; du Feu 2014) and it is important that these are not attributed to the deafness itself. A full physical and developmental assessment is needed, as well as detailed language assessment in speech and/or sign. Conditions such as attention-deficit disorder, dyslexia and autism may be missed, or misdiagnosed as present.

Deaf children may be in mainstream school, specialist units for deaf children in mainstream schools, or in Deaf schools. They may be using speech and/or sign language. An individual deaf child may be appropriately placed, or it may become clear that he or she needs a different provision. Transition from school into adulthood can be a difficult time for all teenagers, and especially so for young deaf people learning to live in what can be an unfriendly hearing society.

As with deaf adults, appropriate communication and cultural understanding is vital for all clinicians seeing deaf children and young people. England has a network of child and adolescent deaf mental health services, but in many areas, including Ireland, these are yet to be developed.

\section{Deaf people with intellectual disability}

Many of the causes of deafness (Box 1), especially those that are non-genetic, can also cause intellectual disability (Kiani 2010). With earlier recognition of deafness, cognitive assessment can take place in early life. However, there are partially and profoundly deaf adults who have not had formal cognitive testing and yet are assumed to have some intellectual disability because of poor educational attainment or reduced social functioning. Psychological assessment of deaf adults, particularly profoundly Deaf sign language users, can give rise to significant errors. The verbal tests of, for example, the Wechsler Adult Intelligence Scale (WAIS-IV) should not be used if English is not a person's first language (Wechsler 2010). Baker \& Baker (2011) discuss the relevant issues. A language-deprived Deaf person may not, for example, arrange picture sequences from left to right, be able to follow complicated instructions or be aware of apparently obvious items of general knowledge. Specialist advice should be obtained when assessing deaf people for intellectual disability, as well as using appropriate interpretation.

\section{Deafblind people}

People with both deafness and sight problems face formidable obstacles in communication, mobility and independence. Since deaf people depend on their sight, and blind people on their hearing, deafblindness means not an addition, but a multiplication of barriers to fulfilment in personal life and inclusion in society.

The national charity Sense (www.sense.org.uk), an important source of information and advice about deafblindness, has estimated that there are more than 350000 people in the UK with dual sensory loss, and a survey in the Republic of Ireland (Anne Sullivan Centre 2016) identified over 1700 people. Both figures are an underestimate, as many people, particularly those with later-onset sensory losses, do not present to services. 
The effect of deafblindness is different for each individual. Deafness may come first, as in Usher syndrome, a recessive genetic condition causing early profound deafness and progressive tunnel vision from retinitis pigmentosa. Dual sensory loss may be present from birth, due to rare genetic syndromes such as CHARGE ${ }^{\mathrm{a}}$ or infections such maternal rubella, which may have other effects such as cardiac problems and intellectual disability. Causes of acquired deafblindness include neurofibromatosis type 2 , where benign lesions can occur on the optical and auditory nerves, resulting in stepwise sensory loss. However, the most common causes are those that affect older people through cumulative age-related changes.

Age at onset, speed of onset, the partial or total nature of the sensory losses, and the presence of associated problems all affect the appropriate way to communicate with a deafblind person. For people with good literacy, Braille is one way forward. Signers can change to receiving sign language by holding the signer's hands and using the deafblind manual alphabet. Maximum use of residual hearing, with aids or implants, and large print and reading aids can all help. Mobility training and assistance, and appropriate lighting, colour contrasts and guide rails, all aid independence. The clinician must take advice from the deafblind person and his or her family or carers about the best way to achieve optimal twoway communication (which may change over time) and then provide this consistently. Communication may be slow and tiring, and sufficient time needs to be allowed, with breaks as required.

\section{Older deaf people}

Over $70 \%$ of people over 70 years old have some form of hearing loss, with the most common cause being age-related damage to the cochlea (Action on Hearing Loss 2015). Many older people do not realise or accept their deafness and are reluctant to ask for help. Even if they go to their general practitioner (GP), are referred to audiology services and are given hearing aids, they may not use them because of practical difficulties or painful background noise. Social isolation can occur insidiously, and even when older deaf people present to health services, their communication needs may be unrecognised or ignored. A deaf person may be taken to hospital, asked to sign a consent form and wheeled into an anaesthetic room without their hearing aids or a sign language interpreter. For older Deaf signers, their social contacts may be elderly themselves, making Deaf events and clubs hard to get to. A signing Deaf person may be in a mainstream residential home with minimal communication.
Younger interpreters may not know the older signs the person used at residential school.

If the principles of effective communication with deaf people are not strictly applied to older deaf adults, diagnoses of mental health problems may be missed or mistaken. A deafened person may be depressed, but their social withdrawal attributed to the deafness. A Deaf signer may be assessed with the standard Mini Mental State Examination (Folstein 1975) and wrongly thought to have dementia. Many of the items in this test are not appropriate as they depend on verbal language, and one test involves closing the eyes, cutting off all communication.

It is well established that social isolation is a risk factor in the development of dementia, and research by Lin et al (2011) has shown that acquired deafness is an additional independent risk. It is postulated that progressive deafness can entail an exhaustion of cognitive reserve, which leads to earlier presentation of all-cause dementia. It is therefore even more important to be aware of deafness in older people, and to recognise the value of effective two-way communication.

\section{Mental health assessment}

History-taking and mental state examination with deaf people need special care. The role of a person's deafness in the presenting mental health problem can be overestimated or ignored. Once effective two-way communication and rapport are established, the history must include the nature and age at onset of the deafness, and the cause, if known. There may be other Deaf people in the family, or the cause of deafness may alert the clinician to associated medical or neurological risk factors. If the deafness has been present from early life, language choices and educational experiences are vital factors in a person's life story.

The mental state examination through a sign language interpreter can be a complex task. The interpreter should have experience in mental health work. The Deaf person may have had limited or home-made signs before the mental health problem began. However, sign languages are processed in the brain in the same way as spoken languages, and they are therefore also affected by conditions such as autism, Tourette syndrome, mania, depression, dementia and the thought disorder of schizophrenia.

Symptoms such as auditory hallucinations, which are well documented as experienced by profoundly Deaf people, can be difficult to identify accurately (du Feu 1999). Some ideas may appear delusional, when in fact the person has just had poor access to information.
MCO answers

$1 \mathrm{~b} \quad 2$ e 3 e $4 d \quad 5$ e

a. CHARGE is the acronym for coloboma, heart defect, atresia choanae, retarded growth and/or development, genital hypoplasia, ear anomalies/deafness. 
Therefore, booking a sign language interpreter is not always the complete answer to the assessment of the mental health of a Deaf person. If there are complex difficulties, advice must be sought from social workers with deaf people, deaf organisations and specialist mental health and deafness services.

\section{Conclusions}

Deaf people, including culturally Deaf sign language users, have equal rights to full participation in society, and this should include access to and appropriate treatment by all healthcare services. However, gaps in the training and awareness of health professionals and frontline staff can lead to barriers and delays that disadvantage deaf people and can put them at risk. Deaf awareness and informed attitudes will lead to equal treatment for this significant proportion of service users.

\section{References}

Action on Hearing Loss (2015) Hearing Matters. Royal National Institute for Deaf People (http://www.actiononhearingloss.org.uk/supporting-you/ policy-research-and-influencing/research/hearing-matters.aspx).

Anne Sullivan Centre (2016) How common is deafblindness? Anne Sullivan Centre for Deafblind People (http://www.annesullivan.ie/aboutdeafblindness). Accessed 11 January 2016.

Baker K Baker F (2011) The assessment of intellectual disability with deaf adults. International Journal on Mental Health and Deafness, 1: 23-36.

Beethoven L van (1802) Heiligenstadt testament. In The Quiet Ear: Deafness in Literature (ed B Grant): 71-3. André Deutsch.

Denmark JC (1994) Deafness and Mental Health. Jessica Kingsley Publishers.

du Feu M, McKenna P (1999) Prelingually profoundly deaf schizophrenia patients who hear voices: a phenomenological analysis. Acta Psychiatrica Scandinavica, 97: 1-9 du Feu M, Ferguson K (2003) Sensory impairment and mental health. Advances in Psychiatric Treatment, 9: 95-103.

du Feu M, Chovaz C (2014) Mental Health and Deafness. Oxford University Press.

Faroog S, Fear C (2003) Working through interpreters. Advances in Psychiatric Treatment, 9: 104-9.

Fellinger J, Holzinger D, Pollard R (2012) Mental health of deaf people. Lancet, 379: 1037-44.

Folstein MF, Folstein SE, McHugh PR (1975) 'Mini-mental state': a practical method for grading the cognitive state of patients for the clinician. Journal of Psychiatry Research, 12: 189-98.

Gentili N, Holwell A (2011) Mental health in children with severe hearing impairment. Advances in Psychiatric Treatment, 17: 54-62.

Kiani R, Miller H (2010) Sensory impairment and intellectual disability. Advances in Psychiatric Treatment, 16: 228-35.

Kvam MH, Loeb M, Tambs K (2006) Mental health in adults: symptoms of anxiety and depression among hearing and deaf individuals. Journal of Deaf Studies and Deaf Education, 12: 1-7.

Lin FR, Metter EJ, O'Brien RJ, et al (2011) Hearing loss and incident dementia. Archives of Neurology, 68: 214-20.

LINK (2005) Hidden Lives: The Psychological and Social Impact of Becoming Deafened in Adult Life. LINK Centre for Deafened People.

Mandela N (2011) Nelson Mandela by Himself. Pan Macmillan South Africa.

Middleton A (ed) (2009) Working with Deaf People: A Handbook for Healthcare Professionals. Cambridge University Press.

Sacks 0 (1991) Seeing Voices: A Journey into the World of the Deaf. Picador.

Sign Health (2014) Sick of It: How the Health Service is Failing Deaf People. Sign Health.

Stokoe WC, Casterline DC, Cronebert CG (1976) A Dictionary of American Sign Language on Linguistic Principles (rev edn). Linstok Press.

Wechsler D (2010) Testing examinees who are deaf or hard of hearing. In Wechsler Adult Intelligence Scale - Fourth Edition (WAIS-IV): Administration and Scoring Manual. pp. 12-19. Pearson.

World Health Organization (2015) Deafness and Hearing Impaired: Fact Sheet No. 300. WHO

World Health Organization (2016) Childhood Hearing Loss: Act Now, Here's How! WHO.

\section{MCOs}

Select the single best option for each question stem

\section{Most deaf people:}

a use sign language

b can feel left out in social situations

c are confident in telling people that they are deaf

$\mathrm{d}$ are treated as considerately as blind people

e need you to speak very loudly to them.

2 Hearing aids:

a are easy to use

b are used by most people who need them

c give good directional hearing

$\mathrm{d}$ mean that people do not need to lipread

e can pick up troublesome background noise
3 Deaf people:

a visit their GP more frequently

b rarely have sight problems

c can all be communicated with by writing

$\mathrm{d}$ have a low prevalence of chronic conditions such as diabetes

e may not understand what is said in medical appointments.

4 Most Deaf people who sign:

a are born into Deaf families

b have used sign from early life

c can be seen with a hearing relative to aid communication during a clinical consultation

$\mathrm{d}$ have poor access to health information e are unlikely to have a mental health problem.
5 Older people:

a have a low rate of hearing loss

b with hearing loss have a reduced risk of dementia

c are highly likely to seek help for their hearing loss

$\mathrm{d}$ with hearing and/or sight loss are unlikely to live alone

e with acquired deafness are at increased risk of social isolation. 